\title{
The effect of vitamin $C$ on the common cold
}

\author{
Harri Hemilä \\ Department of Public Health, \\ University of Helsinki, Finland \\ harri.hemila@helsinki.fi \\ http://www.mv.helsinki.fi/home/hemila
}

This is a manuscript version of:

Hemilä $\mathrm{H}$. The effect of vitamin $\mathrm{C}$ on the common cold.

J Pharm Pract. 2011 Apr;24(2):241-2.

http://dx.doi.org/10.1177/0897190010392376

http://www.ncbi.nlm.nih.gov/pubmed/21712220

The above paper comments on:

Herbs and Other Dietary Supplements:

Current Regulations and Recommendations for Use

to Maintain Health in the Management of

the Common Cold or Other Related Infectious Respiratory Illnesses.

Mathes A, Bellanger R.

J Pharm Pract. 2010;23(2):117-127

http://dx.doi.org/10.1177/0897190009358711

http://www.ncbi.nlm.nih.gov/pubmed/21507804 
Proponents of evidence-based medicine (EBM) emphasize that conclusions about medical interventions should be based on controlled trials with clinically relevant outcomes, so that the greatest weight should be given to the systematic reviews of the trials. One of the most comprehensive EBM databases is the Cochrane Library, which contains thousands of systematic reviews on medical interventions.

The Cochrane review on vitamin $\mathrm{C}$ and the common cold analyzed 29 trial comparisons on the preventive effects of vitamin C, 29 comparisons on the effect of regular vitamin $\mathrm{C}$ on common cold duration and severity, and 7 comparisons on the therapeutic effect of vitamin C (1). The review concludes: "Implications for practice: The prophylaxis trials found a reduction in common cold duration of $8 \%$ in adults and $13 \%$ in children... So far, therapeutic supplementation has not been shown to be effective. Nevertheless, given the consistent effect of vitamin $C$ on duration and severity in the regular supplementation studies, and the low cost and safety, it may be worthwhile for common cold patients to test on an individual basis whether therapeutic vitamin $C$ is beneficial for them." In their review discussing the effect of dietary supplements on the common cold, Mathes and Bellanger refer to 9 papers and state that "various trials have shown no difference in either duration, or severity of symptoms, when vitamin $C$ was compared to placebo. In addition, numerous trials have shown no difference regarding the most commonly studied endpoint: frequency of symptoms"'(2). Since the conclusions of the Cochrane review diverge considerably from the conclusions of Mathes and Bellanger, it is useful to look at the findings of the studies they refer to. Some of the findings are inconsistent with their statements.

Pitt and Costrini found statistically significant $(\mathrm{P}[2-$ tail $]=.024)$ yet small reduction in common cold severity among US Marines who were administered 2 g/day vitamin C $(3,4)$. Van Straten and Joslin reported a highly significant reduction in the number of participants who had 2 colds during their trial (2/84 vs 16/84; $\mathrm{P}=.0004)$ by $1 \mathrm{~g}$ /day vitamin $\mathrm{C}(4,5)$. Ludvigsson et al found a $14 \%$ reduction $(\mathrm{P}=.016)$ in the duration of "absence from school because of upper respiratory tract infection” in their main trial, and a 39\% reduction $(\mathrm{P}=.004)$ in the duration of “upper respiratory tract infection” in their smaller trial when schoolchildren were administered $1 \mathrm{~g} /$ day of vitamin $\mathrm{C}(4,6)$.

Terrence Anderson carried out 3 vitamin C trials in Canada in the 1970s. In their first trial, Anderson et al administered $1 \mathrm{~g}$ /day vitamin $\mathrm{C}$ regularly and $3 \mathrm{~g}$ /day extra when a participant caught the common cold. They found a 30\% (P = .01) decrease in the number of days confined indoors in the vitamin C group (7). Furthermore, staying free of illness during the study period is also a relevant measure of effect and Anderson et al found 8 percentage point increase in the proportion of participants who were "not ill during the trial," "not confined to the house," and "not off work" in the vitamin C group $(\mathrm{P}=.01)(4,7)$. In their second trial, Anderson et al were 
ambitious and they had 2 placebo arms and 6 vitamin C arms with different dosages (8). There were technical problems such as the mislabeling of bottles of tablets $(4,8)$, and therefore no firm conclusions can be drawn from the second trial. Nevertheless, in the vitamin $\mathrm{C}$ arm which was administered $8 \mathrm{~g}$ of vitamin $\mathrm{C}$ only on the first day, 6.6 percentage points $(\mathrm{P}=.046)$ more participants had colds lasting for only 1 day, compared with the arm administered $4 \mathrm{~g}$ of vitamin C, which suggests dose dependency (4). In their third trial, Anderson et al administered 1 to $1.5 \mathrm{~g} /$ day of vitamin C therapeutically so that supplementation was initiated when a person caught a cold. They found a reduction in "days spent indoors per subject" by $25 \%(\mathrm{P}=.048)$ among the vitamin $\mathrm{C}$ participants $(4,9)$.

These 7 controlled trials described above do not support Mathes and Bellanger's statements although the studies are provided as references. Furthermore, Mathes and Bellanger do not describe their rationalization to select the 9 references out of several dozens. In systematic reviews, it is important to describe the selection criteria, in order to prevent bias caused by selecting studies that are consistent with the reviewers' preconceptions. If Mathes and Bellanger were not ready to carry out their own systematic review, they should have taken a look at the Cochrane review which used explicit selection criteria and included all studies fulfilling those criteria.

The main findings of the Cochrane review are as follows. In 5 trials with participants under heavy acute physical stress (3 with marathon runners), vitamin $\mathrm{C}$ reduced the incidence of colds by $52 \%$ (95\% CI: $36 \%$ to $65 \%$ ), but there is no evidence that vitamin C prevents colds in the general population. In regular supplementation trials, $\geq 0.2 \mathrm{~g}$ /day of vitamin $\mathrm{C}$ shortened colds in adults by $8 \%(\mathrm{P}=.0002)$ and in children by $13 \%(\mathrm{P}=.0003)(1)$. It is possible that the same dose causes greater effect on children and that there is dose-dependency so that higher doses lead to a greater benefit (10). When the child trials using less than $1 \mathrm{~g} /$ day of vitamin $\mathrm{C}$ were removed, the pooled estimate of benefit was increased to a $17 \%$ (95\% CI: 8\% to 26\%) reduction in the duration of colds of children (1). Few therapeutic trials have been carried out and none of them with children. Therefore, no firm conclusions about therapeutic vitamin $\mathrm{C}$ can be drawn.

Given that dozens of trials on vitamin $\mathrm{C}$ and the common cold have been carried out with different populations and different dosages, etc, the interpretation of published studies is not quite simple. For example, there is some evidence indicating that vitamin $\mathrm{C}$ may have different effect on males and females $(11,12)$. The most recent trial on vitamin $\mathrm{C}$ and the common cold studied the effect of regular $1 \mathrm{~g} /$ day vitamin $\mathrm{C}$ on adolescent swimmers. There was significant difference between males and females, so that vitamin $\mathrm{C}$ had no effect on females, but shortened the duration of colds in male swimmers by $47 \%$ (95\% CI: $14 \%$ to $80 \%$ ) (13).

Although there is strong evidence that regular vitamin $\mathrm{C}$ shortens the duration of colds, we do not know what is the effect of therapeutic vitamin C, which means starting administration 
after the onset of symptoms. Also, it is possible that there are variations in the vitamin $\mathrm{C}$ effect depending, for example, on dietary vitamin $C$ intake and contact with young children $(4,7,9)$ and sex (11-13). Although there are a number of important questions remaining, it may be worthwhile for common cold patients to test on an individual basis whether therapeutic vitamin C is beneficial for them.

The journal published the following text after the above commentary:

The authors of the CE article, "Herbs and Other Dietary Supplements: Current Regulations and Recommendations for Use to Maintain Health in the Management of the Common Cold or Other Related Infectious Respiratory Illnesses” have no comments. 


\section{References}

1. Hemila H, Chalker EB, Douglas RM. Vitamin C for preventing and treating the common cold. Cochrane Database Syst Rev. 2007;(3):CD000980.

http://dx.doi.org/10.1002/14651858.CD000980.pub4 (2013 update)

2. Mathes A, Bellanger R. Herbs and other dietary supplements: current regulations and recommendations for use to maintain health in the management of the common cold or other related infectious respiratory illnesses. J Pharm Pract. 2010;23(2):117-127.

http://dx.doi.org/10.1177/0897190009358711

3. Pitt HA, Costrini AM. Vitamin C prophylaxis in marine recruits. JAMA. 1979;241(9):908-911. http://dx.doi.org/10.1001/jama.1979.03290350028016

4. Hemila $\mathrm{H}$. Do vitamins $\mathrm{C}$ and $\mathrm{E}$ affect respiratory infections? [PhD Thesis].

Helsinki, Finland: University of Helsinki; 2006: 25-27, 35, 39-42, 44-47.

http://hdl.handle.net/10138/20335

5. Van Straten M, Josling P. Preventing the common cold with a vitamin C supplement:

a double-blind, placebo-controlled survey. Adv Ther. 2002;19(3):151-159.

http://dx.doi.org/10.1007/BF02850271

6. Ludvigsson J, Hansson LO, Tibbling G. Vitamin C as a preventive medicine against common colds in children. Scand J Infect Dis. 1977;9(2):91-98. http://www.ncbi.nlm.nih.gov/pubmed/897573

7. Anderson TW, Reid DBW, Beaton GH. Vitamin C and the common cold: a double-blind trial [correction: 1973;108(2):133]. Can Med Assoc J. 1972;107(6):503-508. http://www.ncbi.nlm.nih.gov/pmc/articles/PMC1940935 http://www.ncbi.nlm.nih.gov/pmc/articles/PMC1941144

8. Anderson TW, Suranyi G, Beaton GH. The effect on winter illness of large doses of vitamin C. Can Med Assoc J. 1974;111(1):31-36. http://www.ncbi.nlm.nih.gov/pmc/articles/PMC1947567

9. Anderson TW, Beaton GH, Corey PN, et al. Winter illness and vitamin C: the effect of relatively low doses. Can Med Assoc J. 1975;112(7):823-826. http://www.ncbi.nlm.nih.gov/pmc/articles/PMC1958969

10. Hemila H. Vitamin C supplementation and common cold symptoms: factors affecting the magnitude of the benefit. Med Hypotheses. 1999;52(2):171-178.

http://dx.doi.org/10.1054/mehy.1997.0639 http://hdl.handle.net/10250/8375 Links to references are added

11. Hemila H. Vitamin C intake and susceptibility to the common cold [discussion: 1997;78(5):857-866]. Br J Nutr. 1997;77(1):59-72.

http://dx.doi.org/10.1017/S0007114500002889

http://hdl.handle.net/10138/13886 Links to references are added

http://dx.doi.org/10.1079/BJN19970201

http://hdl.handle.net/10250/8276 Links to references are added

12. Hemila H. Vitamin $C$ and sex differences in respiratory tract infections.

Resp Med. 2008;102(4):625-626.

http://dx.doi.org/10.1016/j.rmed.2007.12.011

http://hdl.handle.net/10250/8280 Links to references are added

13. Constantini NW, Dubnov-Raz G, Eyal BB, et al. The effect of vitamin C on upper respiratory infections in adolescent swimmers: a randomized trial. Eur J Pediatr. 2011;170(1):59-63 http://dx.doi.org/10.1007/s00431-010-1270-z

http://www.ncbi.nlm.nih.gov/pubmed/20689965 